\title{
CAR(-T)s are on the road
}

\author{
Jakob D. Rudzki
}

CAR-T cell therapies (chimeric antigen receptor-T cell therapies) are increasingly becoming part of clinical practice since the approval of two compounds tisagenlecleucel (Kymriah ${ }^{\circledR}$-Novartis, Morris Plains, NJ, USA) and axicabtagene ciloleucel (Yescarta ${ }^{\circledR}$ _Gilead/kite, Santa Monica, CA, USA) in 2017 in the US market and a bit later in 2018 in Europe and other parts of the world, as well. Starting with $\mathrm{r} / \mathrm{r}$ pALL (relapsed/refractory B-cell precursor acute lymphoblastic leukemia) up to the age of 25 years and young adults (Kymriah) and continuing with $\mathrm{r} / \mathrm{r}$ DLBCL (diffuse large B cell lymphoma) (Kymriah and Yescarta), these two indications are currently the main focus of commercial CAR-T cell therapy. However, new compounds for mentioned indications and new compounds for new indications like for multiple myeloma are attracting more and more attention.

In this issue of $M E M O$, two articles address the question of the importance of CAR-T cell therapy as approved therapeutic options besides current standards in pALL and r/r DLBCL. Hopfinger et al. address the issue of having an additional treatment option in $\mathrm{r} / \mathrm{r}$ DLBCL, a disease stadium with a very dismal prognosis [1]. But, besides the outstanding results of long-term follow-ups of both pivotal trials (JULIET [NCT02445248], ZUMA-1 [NCT02348216]), the new upcoming topics of a financial burden and demanding logistics due to CAR-T cell therapy as a "realistic" treatment option are also discussed.

Greinix et al. provided a comprehensive overview of the results and future aspects of ALL treatment in the context of CAR-T cell therapy (universal CAR-Ts serving as "off the shelf" ready-to-use therapeutic agents

\section{Dr. J. D. Rudzki ( $ه)$}

Internal Medicine V, Medical University of Innsbruck, Anichstraße 35, 6020 Innsbruck, Austria

jakob.rudzki@tirol-kliniken.at or dual targeting concepts like CD19 and CD22 together), and its standing in the current treatment algorithm [2].

Two additional articles describe future aspects and current results of interesting approaches of CAR-T cell therapies in the setting of multiple myeloma and AML without any current approval at the moment. Gunsilius et al. summarized some exciting results of diverse constructs targeting BCMA (B-cell maturation antigen) and CD19 - to mention a few - without forgetting recently published or presented results of very similar compounds like bites (bispecific T-cell engagers) in the treatment of $\mathrm{r} / \mathrm{r}$ multiple myeloma after the third line of therapy [3].

Finally, Rudzki et al. focused on the importance of CAR-T cell therapy in $\mathrm{r} / \mathrm{r}$ AML (acute myeloid leukemia), illustrating current results and providing an overview of the most promising cellular strategies to handle $\mathrm{r} / \mathrm{r}$ AML with CAR-T cell- or TCRapproaches [4].

At the end of this CAR-T article-series, the position paper, "Ensuring Center Quality, Proper Patient Selection and Fair Access to Chimeric Antigen Receptor T-cell Therapy: Position Statement of the Austrian CAR-T Cell Network" released by the Austrian CAR-T platform, presents a brief overview of the broad consensus of all CAR-T centers in Austria focusing on the definition of a CAR-T center, proper patient selection and fair access to CAR-T cell therapy [5].

I hope that you will find these selected contributions of high interest and enjoy reading this collection of articles. Also, I am very appreciative of the willingness by the mentioned authors to cooperate in making this series of CART articles possible. I would like to express my gratitude to the contributing authors for their dedication and work. 


\section{editorial}

Conflict of interest J.D. Rudzki declares that he has received honoraria and speaker's fee from BMS, Roche, MSD, AstraZeneca, Amgen, Gilead-kite, Novartis and served as advisor for BMS, Roche, MSD, AstraZeneca, Amgen, Gileadkite, Novartis and Celgene.

\section{References}

1. Hopfinger G, Worel N. CAR T-cell therapy in diffuse large B-cell lymphoma. memo. 2020;13(1). https://doi.org/10. 1007/s12254-019-00558-z.

2. Greinix HT. Role of CAR-T cell therapy in B-cell acute lymphoblastic leukemia. memo. 2020;13(1). https://doi. org/10.1007/s12254-019-00541-8.

3. Steiner N, Gunsilius E. CAR-T cells in multiple myeloma: current status. memo. 2020;13(1). https://doi.org/10. 1007/s12254-020-00571-7.

4. Rudzki J.D., Wolf D. AML-is it time to drive a CAR(-T)? memo. 2020;13(1): https://doi.org/10.1007/s12254-02000577- 1 .
5. Greinix H. et al. Ensuring Center Quality, Proper Patient Selection and Fair Access to Chimeric Antigen Receptor T-cell Therapy: Position Statement of the Austrian CAR-T Cell Network. memo. 2020;13(1): https://doi.org/10.1007/ s12254-020-00582-4.

Publisher's Note Springer Nature remains neutral with regard to jurisdictional claims in published maps and institutional affiliations.

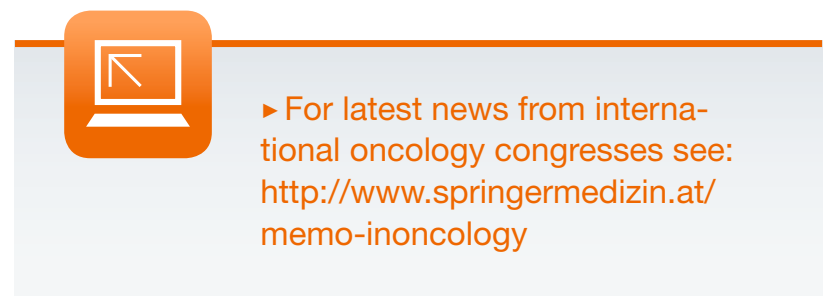

